\title{
High-Flux Stress Testing of Encapsulants for Medium- Concentration CPV Applications
}

Technical Report NREL/TP-520-46648

September 2009

M.D. Kempe and T.J. Moricone National Renewable Energy Laboratory

M. Kilkenny

Skyline Solar

J.Z. Zhang

Atlas Materials Testing Technology LLC 


\section{High-Flux Stress Testing of Encapsulants for Medium- Concentration CPV Applications}

M.D. Kempe and T.J. Moricone National Renewable Energy Laboratory

M. Kilkenny

Skyline Solar

J.Z. Zhang

Atlas Materials Testing Technology LLC

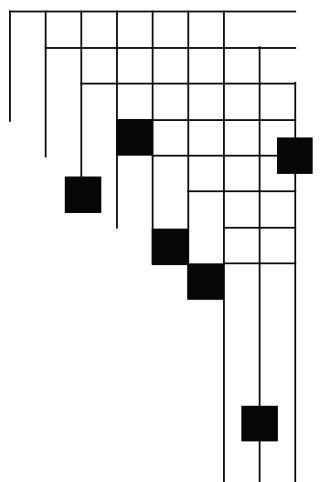

Prepared under Task No. PVD91330 


\section{NOTICE}

This report was prepared as an account of work sponsored by an agency of the United States government. Neither the United States government nor any agency thereof, nor any of their employees, makes any warranty, express or implied, or assumes any legal liability or responsibility for the accuracy, completeness, or usefulness of any information, apparatus, product, or process disclosed, or represents that its use would not infringe privately owned rights. Reference herein to any specific commercial product, process, or service by trade name, trademark, manufacturer, or otherwise does not necessarily constitute or imply its endorsement, recommendation, or favoring by the United States government or any agency thereof. The views and opinions of authors expressed herein do not necessarily state or reflect those of the United States government or any agency thereof.

Available electronically at http://www.osti.gov/bridge

Available for a processing fee to U.S. Department of Energy and its contractors, in paper, from:

U.S. Department of Energy

Office of Scientific and Technical Information

P.O. Box 62

Oak Ridge, TN 37831-0062

phone: 865.576 .8401

fax: 865.576 .5728

email: mailto:reports@adonis.osti.gov

Available for sale to the public, in paper, from:

U.S. Department of Commerce

National Technical Information Service

5285 Port Royal Road

Springfield, VA 22161

phone: 800.553.6847

fax: 703.605.6900

email: orders@ntis.fedworld.gov

online ordering: http://www.ntis.gov/ordering.htm 


\title{
HIGH-FLUX STRESS TESTING OF ENCAPSULANTS FOR MEDIUM- CONCENTRATION CPV APPLICATIONS*
}

\author{
M. D. Kempe ${ }^{1}$, M. Kilkenny ${ }^{2}$, T. J. Moricone ${ }^{1,}$ J. Z. Zhang ${ }^{3}$ \\ ${ }^{1}$ National Renewable Energy Laboratory (NREL), 1617 Cole Boulevard, Golden, CO 80401 \\ ${ }^{2}$ Skyline Solar, 185 E. Dana Street, Mountain View, CA 94041 \\ ${ }^{3}$ Atlas Materials Testing Technology LLC, 4114 N. Ravenswood Ave, Chicago, IL 60613
}

\begin{abstract}
Concentrating photovoltaic (CPV) systems have great potential to reduce photovoltaic (PV) electricity costs because of the low cost of optical components relative to $\mathrm{PV}$ cells. Ultimate success of CPV will require long-term reliability, including stability of the transparent polymeric material that encapsulates the cell, and, therefore, is exposed to concentrated light. It is desireable to evaluate the UV-resistance of these materials in a reasonably short time. In this work we investigated two strategies for enhancing UV exposure, achieving a sustainable intensity of 40-45 suns UV. We applied these strategies to polydimethyl silioxane (PDMS), ethylene vinyl-acetate (EVA), ionomers, and thermoplastic polyurethanes (TPU). Superior performance was found for PDMS materials, but some of the hydrocarbon-based materials could also be suitable for CPV applications.
\end{abstract}

\section{INTRODUCTION}

Concentrating photovoltaic (CPV) systems have great potential to reduce systems cost and the cost of electricity produced by photovoltaic (PV) cells. The relatively small area covered by the cells allows high-performance cells to be used with optical systems that concentrate solar flux by as much as $500 \mathrm{X}$ to $1000 \mathrm{X}$. At geometric concentrations less than $50 \mathrm{X}$, monocrystalline silicon-based cells typically balance the considerations of cell cost and performance. However at high concentration (250X to 1000X) highperformance III/ $\mathrm{V}$ multijunction cells are used exclusively because the high performance of the cells justifies their relatively high cost.

For CPV systems, a transparent polymeric material is typically used to optically couple the PV cell to optical components while also providing electrical insulation against condensed moisture that may create a grounding hazard and/or increase corrosion rates. The light intensity and wavelength distribution are important considerations for choosing an encapsulant because these will vary greatly depending on the focusing optics used [1]. At concentrations $<5 \mathrm{X}$, typical hydrocarbon-based encapsulants, such as ethylene vinyl-acetate (EVA), should be durable over the desired 20-year service lifetime if they are formulated correctly. At concentrations $>50 X$, silioxane-based encapsulants [e.g. polydimethyl silicone (PDMS)] are used as they are extremely resistant to thermal and light-induced degradation. Issues such as the need for expensive Pt-based catalysts in highperformance PDMS formulations typically make them

* A Similar Version was presented at the $34^{\text {th }}$ IEEE Photovoltaics Specialists Conference, June 7-12, 2009, in Philadelphia, Pennsylvania. more costly to use. However, this can be acceptable at high concentration because the performance gains outweigh the costs.

For medium-concentrations systems ( $\sim \mathrm{X}$ to $50 \mathrm{X})$ the choice of encapsulant is less clear. The higher performance and higher durability of PDMS based encapsulants must be considered as an alternative to lower cost and lower performing hydrocarbon-based materials. Because PV system will be in use for 20 or 30 years, evaluating their performance in a reasonably short time can be problematic.

In this study, we developed methods to expose transparent encapsulant materials to high (40 to $45 \mathrm{UV}$ suns) optical fluxes of UV radiation to enable rapid evaluation of materials. Exposure was further modified by changing the glass composition (with and without cerium) to increase the effective UV dose $[2,3]$ relative to that of a typical CPV optical system [1].

We exposed a variety of hydrocarbon and siliconebased materials to this high UV flux and measured the changes in yellowness index (YI) and the quantum efficiency/solar spectrum weighted transmittance. We compare the results to identify candidate encapsulant materials for use under medium concentration and discuss the implications of the test results on expected service in the field. With this method, it is possible to evaluate materials for 20- to 30-yr exposure in mediumconcentration CPV applications in a relatively short time.

\section{EXPERIMENTAL PROCEDURE}

Ultraviolet exposure was obtained using an Atlas Ci4000 Weather-Ometer ${ }^{\circledR}$ with a light intensity of 114 $\mathrm{W} / \mathrm{m}^{2}$ between $300 \mathrm{~nm}$ and $400 \mathrm{~nm}$. The light was filtered using a type " $S$ " borosilicate inner and outer filter. This light intensity (about 2.5X the AM 1.5 global UV Suns) is experienced by samples placed at a radius of $r=32.4 \mathrm{~cm}$ from the lamp. To increase the UV dose, test samples were placed at a radius of $r=7 \mathrm{~cm}$ from the lamp. Here, the UV dose was estimated by approximating the lamp as a $12.5 \mathrm{~cm}$ long line source with the light intensity decreasing as $1 / r^{2}$ from each point along its length.

$$
I=I_{o} \int_{Z_{\text {sample }}-\frac{l}{2}}^{Z_{\text {sample }}+\frac{l}{2}} \frac{1}{z^{2}+r^{2}} d z
$$

Here $z$ is the vertical distance from the center point of the lamp, $r$ is the horizontal radial distance from the lamp, $I$ is the total length of the lamp, and $I_{o}$ is a coefficient for the lamp intensity (See Fig. 1). Integration of Eq. 1 yields,

$$
I=I_{o} \frac{1}{r}\left[\tan ^{-1}\left(\frac{Z_{\text {sample }}+\frac{l}{2}}{r}\right)-\tan ^{-1}\left(\frac{Z_{\text {sample }}-\frac{l}{2}}{r}\right)\right]
$$


where $I_{0}$ can be solved from the known condition that the UV intensity at $r=32.4 \mathrm{~cm}$ and $Z=0 \mathrm{~cm}$ is 2.5 suns.

Using Eq. 2, the intensity at a radius of $r=7 \mathrm{~cm}$ as a function of height was estimated as shown in Fig. 2. To avoid using regions where the light intensity changes rapidly, only the vertically central $Z= \pm 3.8 \mathrm{~cm}$ region was utilized. In this region, the calculated irradiance varies between 39.3 UV suns and 44.0 UV suns with an average of $42.3 \pm 1.5$ UV suns. Whenever a sample was removed for measurement, the positions of all samples were randomized to avoid any location specific variations in light intensity. The Ci4000 Weather-Ometer was set at $30^{\circ} \mathrm{C}$ and $30 \% \mathrm{RH}$ with baffles placed to enhance air flow to the specimens to reduce their temperature. The black panel temperature was set at $29^{\circ} \mathrm{C}$ to force the recirculation blower to continually operate at maximum speed, providing the maximum convective cooling possible.

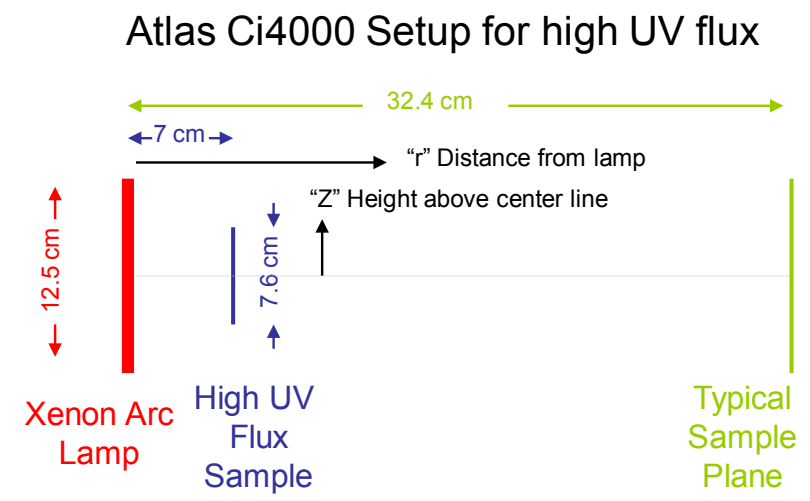

Figure 1. Schematic of Atlas Ci4000 Weather-Ometer in crosssection, with samples placed close to the lamp.

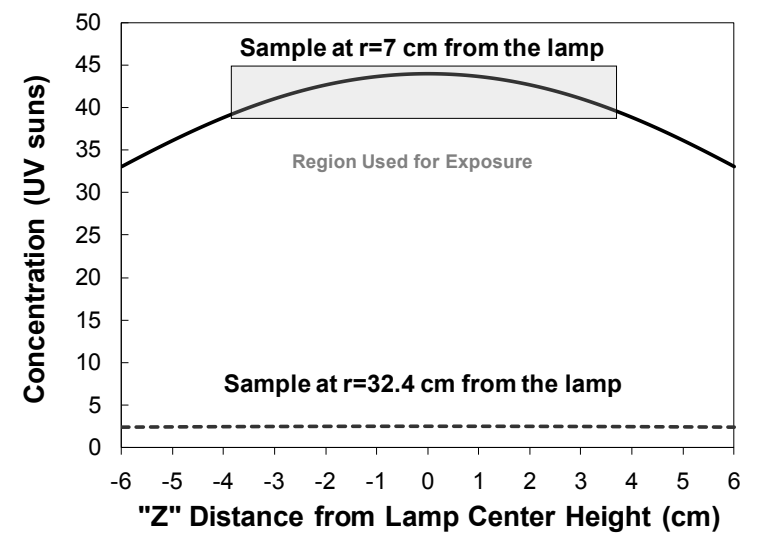

Figure 2. Plot of the calculated light flux along the lamp for $r=7$ and $\mathrm{r}=32.4 \mathrm{~cm}$.

To verify the applicability of Eq. 2, measurements of the light intensity as a function of radial distance $r$ were performed by Atlas weathering services in an Atlas Ci5000 Weather-Ometer using an integrating sphere attached to a fiber optic cable and a spectroradiometer, Fig 3 . The dashed lines indicate a slope of $1 / r^{2}$, which is what one would expect at large distances from a point light source, or the slope of $1 / r$, which is what one would expect for an infinite linear light source. For most of the range of distances measured, the calculated line (Eq. 2) closely matches the measurements. However, at large distances (and low light intensities) the measured values are high, which could be explained from reflected light within the chamber. At small distances $(<7 \mathrm{~cm})$ there is a negative deviation. While this deviation may be attributable to the limitations of the optical measurement, this analysis demonstrates that Eq. 2 is a reasonable representation of the light intensity at most locations within a Xe arc lamp chamber.

At $r=7 \mathrm{~cm}$ in the Ci4000 Weather-Ometer, a deviation in radius $r$ of $\pm 1 \mathrm{~mm}$ corresponds to about $1 \mathrm{UV}$ sun irradiance. When one considers that the ability to position the samples should be accurate to $\pm 3 \mathrm{~mm}$, then the greatest sources of uncertainty in the irradiance comes from the vertical- radial- placement.

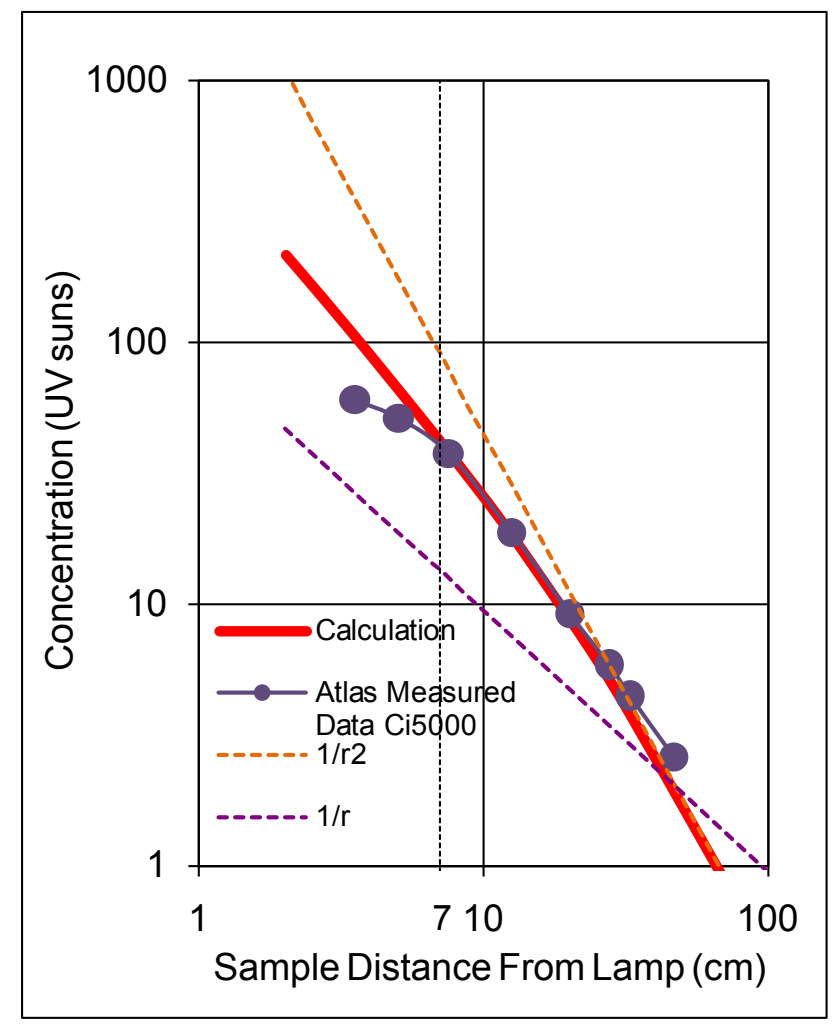

Figure 3. Plot of the calculated light flux on a sample at a fixed height, $z=0$, as a function of radial distance, $r$. The calculation (Eq. 2) applies to an Atlas Ci5000 Weather-Ometer with 2 UV suns at $\mathrm{r}=47 \mathrm{~cm}$ with a $25-\mathrm{cm}$-long bulb.

The samples used in this experiment were made using a $\sim 0.5-\mathrm{mm}$ thick polymer laminated between two $2.5-\mathrm{cm} \times 2.5-\mathrm{cm}, 3.18-\mathrm{mm}$ or $2.95-\mathrm{mm}$ thick glass sheets. Because the samples are transparent, they remained at temperatures between $78^{\circ} \mathrm{C}$ and $95^{\circ} \mathrm{C}$ depending on their age, and hence relative amount of $\mathrm{IR}$ radiation, the $\mathrm{Xe}$ arc lamp emits. It was also observed that as samples begin to discolor and become more optically absorbing, their steady-state temperature increased. Black samples were 
found to reach temperatures as great as 150 to $170^{\circ} \mathrm{C}$. Samples with significant changes in $\mathrm{YI}$ were found to reach temperatures of 110 to $120^{\circ} \mathrm{C}$.

After exposure to UV light, the transmittance of the samples was measured using a Varian Cary 6000i UVVIS-NIR spectrophotometer equipped with an integrating sphere. From this, the yellowness index (YI) was calculated according to ASTM E313 using D65 as the illuminant (solar equivalent) spectrum and the 1931 procedure [4]. Because medium-concentration CPV systems typically use monocrystalline silicon cells, the light transmittance was weighted against the AM 1.5 direct solar spectrum [5] and the quantum efficiency of a typical monocrystalline silicon PV cell.

Some samples began to degrade at their perimeter as an oxidative process dominated the degradation. Others (all EVA samples tested), turned yellow in the center first as an oxidative process serves to remove chromophores at the perimeter. In both cases, these perimeter oxidative effects were limited to the outer millimeters of the samples. Because a cell used in a medium-CPV application (or a non-concentrating system) typically uses a glass front sheet located in front of a relatively large cell, the anaerobic center of our samples is likely to be more representative of the majority of the packaged region useful in a PV application. Therefore, all transmittance measurements were made in the center of the samples. This assumption is more applicable to CPV systems than non-concentrating systems because intense UV irradiation degrades the encapsulant rapidly relative to oxygen diffusion rates which would not be accelerated equally.

\section{RESULTS}

The different encapsulant materials that may be used in CPV each possess unique UV-absorbtion spectra. Even though UV radiation comprises only a small amount of the total solar energy, the photons in this region (especially below $350 \mathrm{~nm}$ ) are extremely effective at degrading polymeric materials [2, 6, 7]. In Fig 4., the transmittance of low-Fe glasses, with and without $\mathrm{Ce}$, are shown to illustrate how the addition of trace amounts of $\mathrm{Ce}$ affects the UV absorption [8]. The addition of $\mathrm{Ce}$ also reduces transmittance of infrared light, yielding a loss in transmittance that develops upon exposure to UV light as shown in Fig. 5. This "solarization" produces a 1\% loss in transmittance for low-Fe, Ce-containing glass along with a 0.2 increase in YI. This small loss in transmittance influenced many in the PV industry to discontinue using glass with $\mathrm{Ce}$. While this may be appropriate for flat-panel $\mathrm{PV}$ systems, medium-X CPV systems may require $\mathrm{Ce}-$ doped glass, or some equivalent UV screen, to enable the use of EVA (as opposed to silicone-based encapsulant materials).

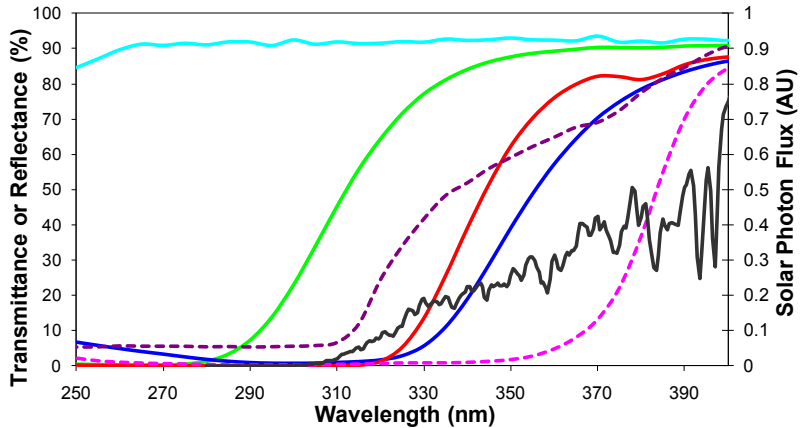

$2.95 \mathrm{~mm}$ low-Fe, non-Ce soda lime glass

$-3.18 \mathrm{~mm}$ low-Fe, Ce containing glass

---Aluminum Mirror - Direct Solar Spectrum

Figure 4. UV transmittance or reflection of representative materials used in CPV applications (glass shown after solarization).

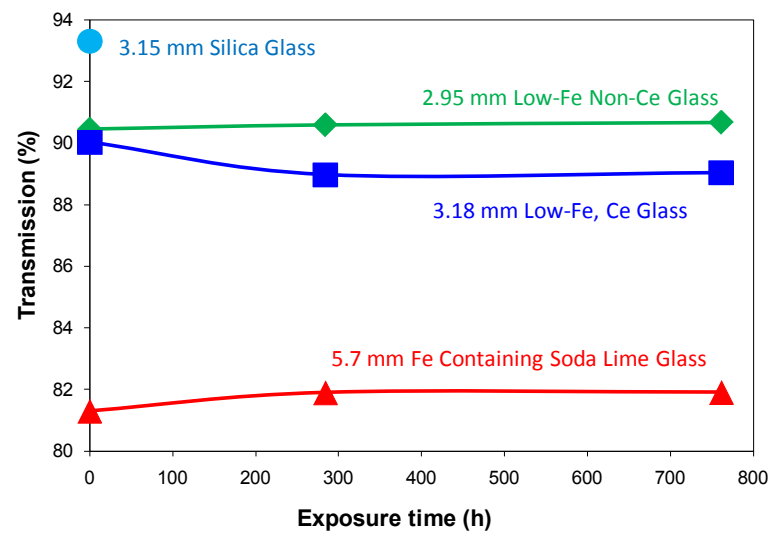

Figure 5. Transmittance as a function of exposure to 42 UV suns.

Four different EVA formulations were obtained from different manufacturers and tested for changes in $\mathrm{YI}$ and optical transmittance as a function of exposure (Fig. 6). Different types of glass were used to demonstrate how blocking UV radiation below $\sim 350 \mathrm{~nm}$ can have a dramatic effect on changes in $\mathrm{YI}$ and optical transmittance. Changes in $\mathrm{Yl}$ correlate well with optical transmittance in all the polymeric materials tested in this study. The $\mathrm{YI}$ values generally display significant changes with less exposure than the weighted transmittance, making them good predictors of material performance. However, the Ce-glass itself produces an initial drop in transmittance over the first $\sim 200 \mathrm{hr}$, attributable to solarization of the glass, that does not correlate with a significant change in yellowness index. In Fig. 6, one can see significant differences between the EVA formulations illustrating the importance of using a well-formulated EVA.

Because the loss of transmittance causes significant heating via optical absorption, the exact shape of the different curves might not be useful for comparison between different samples. Initially, all samples should be at nearly the same temperature, but as they become more absorbing, thermally induced degradation may further increase degradation rates. However, the onset of 
degradation should correlate well with UV dose, as thermal runaway doesn't occur until after significant degradation has accumulated.

After $1000 \mathrm{~h}$ all the non-Ce EVA samples began to show some changes in $\mathrm{YI}$, whereas none of the $\mathrm{Ce}$ containing samples show statistically significant increases in YI until after $2000 \mathrm{~h}$. Transmittance for EVA \#2 behind Ce-containing glass, appears to be dropping at $2000 \mathrm{~h}$ but lack of data between $2000 \mathrm{~h}$ and $4000 \mathrm{~h}$ indicates it could be longer than $4000 \mathrm{~h}$ before significant degradation occurs. For EVA \#1 behind Ce-containing glass, somewhere between 2000 and $4000 \mathrm{~h}$ the sample began to delaminate. Therefore, further transmittance characterization was not possible. This sample will be reexamined to determine if delamination is an inherent problem for this formulation.
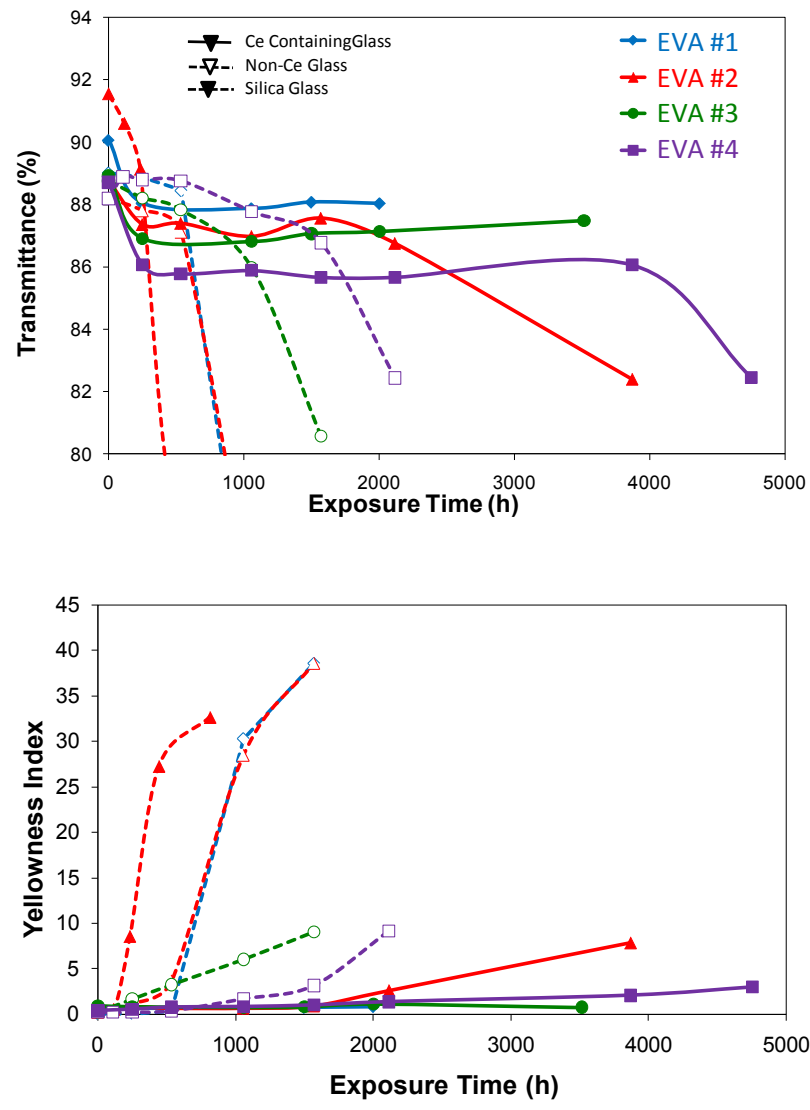

Figure 6. Transmittance and yellowness index for different EVA materials as a function of exposure to 42 UV suns of radiation behind different glass materials.

The yellowness index gave similar results to the transmittance measurements. For EVA sample \#2, onset of significant changes in $\mathrm{YI}$ and Transmission occur at 2000 h, $500 \mathrm{~h}$, and $100 \mathrm{~h}$ for $\mathrm{Ce}$, non-Ce, and silica glass respectively. Fig. 7 demonstrates the visual appearance of a typical EVA sample. The ingress of oxygen from the perimeter bleaches the chromophores making the samples more transparent around the edges [6, 9]. This trend continued with time, and at $1568 \mathrm{~h}$ (Fig. 8) the UV-blocking Ce glass sample is still relatively transparent as compared to the non-Ce sample. However, after $4000 \mathrm{~h}$ of exposure behind Ce-containing glass, EVA \# 1, \#2 and \#4 (and \#3 to a much lesser extent) are discolored around the oxygen-exposed perimeter as opposed to the more anaerobic center (Fig. 9). This demonstrates that there are at least two different processes causing yellowing.

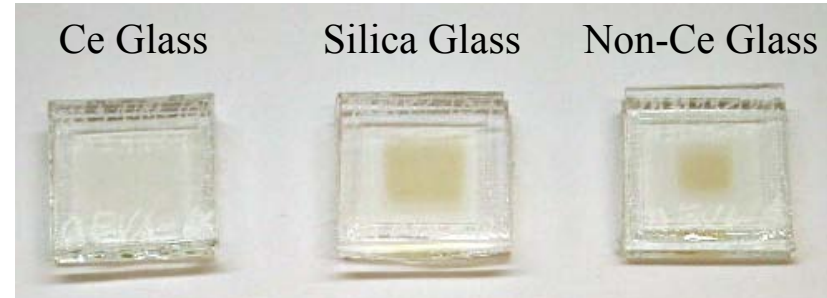

Figure 7. EVA \#5 after $400 \mathrm{~h}$ of 42 UV suns. Samples are 2.5$\mathrm{cm} \times 2.5-\mathrm{cm}$ square.

For EVA \#2, it can be seen that the removal of $\mathrm{Ce}$ causes the onset of transmittance loss to occur about 4 to $6 \mathrm{X}$ faster. For EVA \#2 a sample was made using silica glass for which the onset of transmittance loss was almost immediate. This identifies the high potential of UV-B $(285<\lambda<320 \mathrm{~nm})$ to cause degradation. This estimate of a 4 to $6 \mathrm{X}$ reduction in the time required for the onset of degradation is probably a low estimate for switching from Ce to non-Ce glass [10]. The observation that most of the EVA formulations laminated to Ce glass maintained good transmittance during extended exposure, indicates that the blocking of UV-B light may generally reduce discoloration by more than $6 \mathrm{X}$. On the time scale of these experiments, it is apparent that oxygen has not fully permeated the samples; therefore, this result may not be applicable to non-concentrating systems where there may be sufficient time for oxygen ingress for photo-oxidative bleaching.

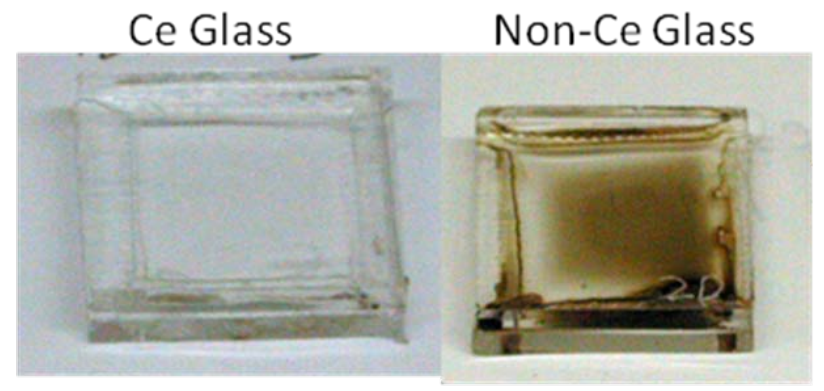

Figure 8. EVA \#2 after 1568 h of 42 UV suns. Samples are 2.5$\mathrm{cm} \times 2.5-\mathrm{cm}$ square. 


\section{Ce Glass}

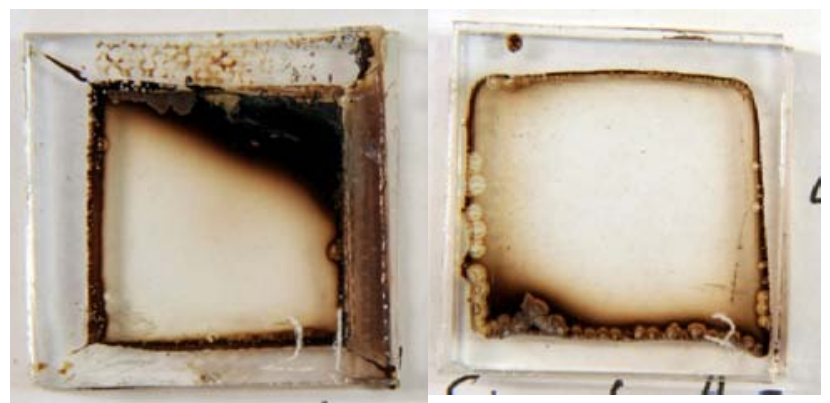

Figure 9. EVA \#2 (left) EVA \#4 (Right) after $4125 \mathrm{~h}$ of 42 UV suns. Samples are $2.5-\mathrm{cm} \times 2.5-\mathrm{cm}$ square.

Other hydrocarbon-based polymers were examined (Fig 10). Only the ionomer showed better performance relative to EVA. The thermoplastic polyurethane (TPU) was comparable to EVA in its $\mathrm{YI}$ and transmittance changes. It also showed photo-oxidative bleaching around the perimeter in the non-Ce glass sample but not the Ceglass sample after $4000 \mathrm{~h}$. However, the non-Ce glass TPU sample delaminated after $2000 \mathrm{~h}$ of exposure.

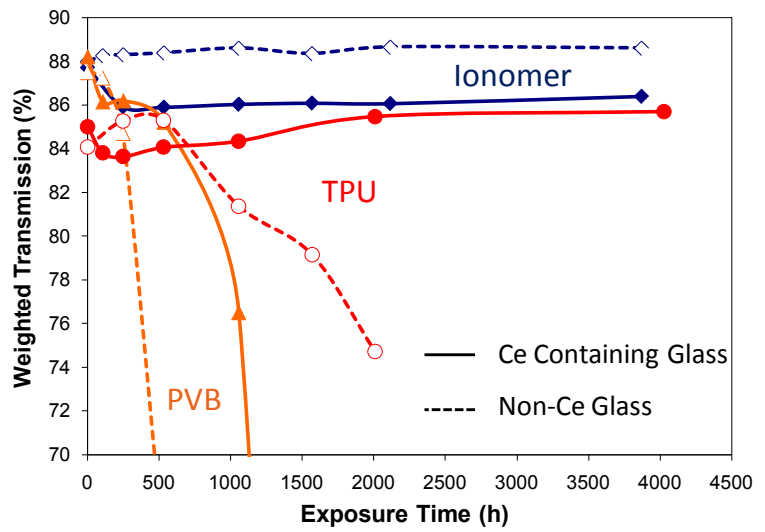

Figure 10. QE- and solar-weighted transmittance for a thermoplastic polyurethane (TPU), an ionomer, and polyvinyl butyral (PVB) as a function of exposure to 42 UV suns. The changes in $\mathrm{YI}$ for the ionomer, PVB and TPU correlate well with changes in optical transmittance.

The polyvinyl butyral (PVB) samples in particular degraded quickly with time, even with the UV-blocking Ceglass. The PVB tested turned yellow in all areas exposed to UV radiation; there were no perimeter yellowing or oxidative bleaching effects. For the PVB sample, it can be seen that the use of non-Ce glass causes degradation to begin about 2 to $5 X$ faster relative to Ce-containing glass.

While the transmittance data for the ionomer showed no degradation after nearly $4000 \mathrm{~h}$, visual inspection of the sample clearly shows some photo-oxidative degradation that is more significant for the non-Ce glass (Fig. 11). In the figure, optical degradation is located on the perimeter

indicating that it is an oxygen-induced degradation. Furthermore, the non-Ce glass sample shows more degradation suggesting that the process is accelerated by UV radiation (especially the UV-B spectrum).

\section{Non-Ce Glass}

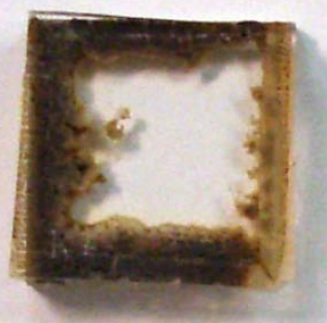

\section{Ce-Containing Glass}

Figure 11. Photograph of the ionomer samples after $3900 \mathrm{~h}$ of exposure to 42 UV suns. Samples are $2.5-\mathrm{cm} \times 2.5-\mathrm{cm}$ square.

The PDMS samples examined performed exceptionally well (Fig. 12). With a $\pm 1 \%$ uncertainty in transmittance measurements, the only statistically significant changes in the silicone samples pertain to solarization of the Ce-containing glass and not silicone degradation. These silicone-based encapsulant samples clearly show superior performance as compared to all the hydrocarbon-based materials. There were no visual signs of degradation, even on the perimeters, of any of these samples.

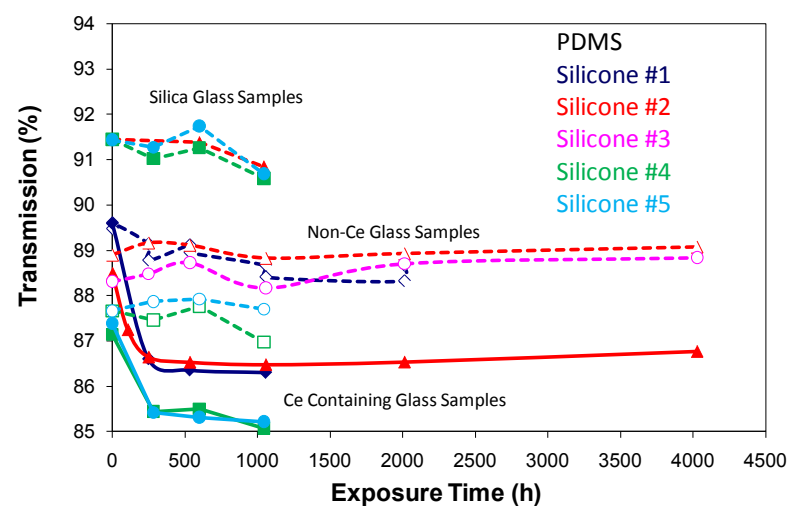

Figure 12. Measured optical transmittance for PDMS specimens. No changes in $\mathrm{Yl}$ were observed.

\section{DISCUSSION}

At 42 UV suns running $24 \mathrm{hr} /$ day, our modified test instrument provides a UV dose that is about $42 \times 3=126$ times as damaging as typical outdoor field exposure on a solar tracker. Therefore, $1000 \mathrm{~h}$ of exposure roughly corresponds to about 14 years at 1 sun, provided a linear relationship exists between exposure intensity and degradation. This assumption is tenuous at the extreme exposure conditions utilized here, but when making comparisons to CPV systems at $10 \mathrm{X}$ to $50 \mathrm{X}$, this 
assumption is more robust because the instantaneous dose is about 4.2 times as intense. Typically, the dependence on UV dose at high concentrations is sublinear (i.e. 10 suns renders less than $10 \mathrm{X}$ acceleration) $[11,12,13]$. Furthermore, an Atlas Weather-Ometer configured with a borosilicate inner and outer filter on the xenon arc lamp, is designed to emulate the global spectrum not the direct solar spectrum utilized in CPV applications. The direct spectrum has $30.5 \mathrm{~W} / \mathrm{m}^{2}$ and the global spectrum has $46.1 \mathrm{~W} / \mathrm{m}^{2}$ between $300 \mathrm{~nm}$ and 400 $\mathrm{nm}$; therefore, there is another $1.5 \mathrm{X}$ acceleration factor for concentrating systems. This results in an irradiance of $42 X 3 X 1.5=190$ times the direct UV solar spectrum.

If these are the only factors being considered, it would take about $9,300 \mathrm{~h}$ (1.1 years) for 20 years equivalent exposure in a system operating at $10 \mathrm{X}$ concentration and $46,000 \mathrm{~h}$ (5.3 years) for a 20-year equivalent exposure for a system operating at $50 \mathrm{X}$ concentration.

The equivalent test time can be further reduced if one considers that the mirrors and polymeric Fresnel lenses used in CPV applications act to reduce the amount of UV light transmitted as concentrated light, Fig. 4. Mediumconcentration CPV systems typically use linear concentration in the form of Fresnel mirrors or lenses or trough reflectors.

Fresnel lenses are typically constructed using an acrylate polymer (e.g. polymethyl methacrylate) that is stabilized using UV absorbers that will yield a transmittance profile similar to the UV-absorbing film shown in Fig. 4. Because this spectral distribution blocks much more UV light than the glass superstrates tested here, extrapolation to this condition would be very tenuous. It is anticipated with so little UV light, that other processes, such as thermal degradation, may instead dominate [1].

For the case of a mirror used to concentrate light prior to transmittance through a low-Fe non-Ce glass, inspection of Fig. 4 indicates that the spectral distribution would roughly be represented by the transmittance through a low-Fe, Ce-containing glass. In this work, exposure to high UV flux has indicated that the removal of Ce from glass causes degradation to occur between 2 and $6 \mathrm{X}$ faster. If one assumes the performance of samples behind non-Ce glass compares to a mirror/non-Ce glass concentrating system, then an additional $4 X$ acceleration factor can be assumed as a first-order approximation bringing the total acceleration factor to $190 \times 4=760$. With these assumptions, samples behind low-Fe, non-Ce glass exposed for $2,300 \mathrm{~h}$ or $12,000 \mathrm{~h}$ emulate $20 \mathrm{yr}$ in the field for 10X and 50X CPV systems, respectively. Because the effects of oxygen ingress are not adequately controlled in this experiment, and because the extra UV-B radiation with non-Ce glass has the potential to accelerate nonrepresentative failure modes, this extra $4 X$ acceleration should be used with caution.

All the silicone materials have so far demonstrated this criteria ( $>2000 \mathrm{~h}$ exposure) for the 10X CPV conditions. It is expected that they will continue to perform well for the 50X-CPV-equivalent exposure. For the hydrocarbon-based materials, only the ionomer (see Figs.
6 and 8) demonstrates UV stability for 10X-CPV applications. Continued study will examine the 50X-CPVexposure condition. Even if it does continue to perform well, the perimeter degradation shown in Figure 9 is an important concern. Significant material degradation around the perimeter could create an electrical insulation hazard before the optical degradation affected module performance. However, extra UV protection around the oxygen-exposed parts may be sufficient to alleviate this concern. Further study is necessary to confirm this.

Another aspect to consider for materials selection is the total light transmittance. In prior work, it was estimated that PDMS silicones transmit about $0.7 \%$ more light (for normal incidence) than some of the best hydrocarbonbased materials (e.g. EVA and PVB) [3]. With continued exposure, further reductions in light transmittance is expected relative to the silicone-based materials. This $0.7 \%$ difference in performance should be considered as a minimum because properly formulated PDMS materials are less likely to experience transmittance losses after UV exposure. If the price difference between using a silicone and a hydrocarbon-based material is less than $0.7 \%$ of the overall module price, then a silicone is likely to be the more cost effective solution. As the concentration ratio gets higher, the relative amount of area (and materials) required to encapsulate a module will decrease making the case for a silicone-based encapsulant stronger.

Lastly, this analysis has only considered the effects of degradation on light transmittance. An encapsulant material must also maintain good adhesion. If delamination occurs, there will likely be enhanced corrosion, a loss of light transmittance (associated with interfacial reflectance), and the potential for a safety hazard (arc or grounding fault). This safety hazard could make the system inoperable which is the greatest of these concerns.

\section{CONCLUSION}

A method was developed for exposing transparent encapsulant materials to $42 \pm 5$ UV suns of radiation. Test samples were constructed using $\mathrm{Ce}$ - and non-Cecontaining glass superstrates to further increase the UV dose. It was found that samples with non-Ce glass, which transmit more UV light, causes a loss of transmittance in a polymeric material somewhere between 2 and $6 \mathrm{X}$ faster than UV blocking Ce-containing glass.

As a first-order approximation, it was estimated that under these conditions a UV dose equivalent to 20 years for a system using mirrors and non-Ce glass can be obtained in 2,300 $\mathrm{h}$ and $12,000 \mathrm{~h}$ for 10X and 50X CPV systems, respectively. However, exposing samples to a UV-B rich environment has the potential to introduce nonrepresentative degradation; therefore, if the spectrum is matched to the direct solar spectrum, 9,300 $\mathrm{h}$ and 46,000 $\mathrm{h}$ would instead be required for a $10 \mathrm{X}$ and 50X CPV system, respectively. This allows for evaluation of candidate materials in a more reasonable amount of time.

For the PDMS materials, no signs of degradation were seen after as long as $4000 \mathrm{~h}$ of exposure to $42 \mathrm{UV}$ 
suns. The best hydrocarbon-based polymer tested was an ionomer. After $4000 \mathrm{~h}$ of exposure, no change in transmittance or $\mathrm{YI}$ index was observed within the central portion of the ionomer samples; however, the edges that were exposed to air experienced severe UV-induced degradation. If adequate protection of these exposed surfaces were provided, it might be possible to use this material in a medium-concentration CPV application.

\section{ACKNOWLEDGEMENTS}

We would like to thank Rafael de la Vega for help with the Weather-Ometer irradiance measurements. David Miller and Sarah Kurtz for helpful discussions and review of this work. And Marc Oddo for providing representative mirror data. This work was supported by the U.S. Department of Energy under Contract No. DOE-AC3608G028308 with the National Renewable Energy Laboratory.

\section{REFERENCES}

[1] D.C. Miller, M.D. Kempe, C.E. Kennedy, and S.R. Kurtz,

"Analysis of Transmitted Optical Spectrum Enabling Accelerated Testing of CPV Designs", Proc. SPIE, 2009, 7407-16.

[2] M.D. Kempe, "Accelerated UV Test Methods and Selection Criteria for Encapsulants of Photovoltaic Modules", 33rd IEEEPVSC, San Diego, CA (2008).

[3] A. L. Andrady, Wavelength Sensitivity in Polymer Photodegradation, Advances in Polymer Science 128, 49-94 (1997).

[4] ASTM E313-05 Standard Practice for Calculating Yellowness and Whiteness Indices from Instrumentally Measured Color Coordinates.

[5] ASTM G 173-03, Standard Tables for Reference Solar Spectral Irradiances: Direct Normal and Hemispherical on 37o Tilted Surface.

[6] P. Klemchuk, M. Ezrin, G. Lavigne, W. Holley, J. Galica, S. Agro, Investigation of the Degradation and Stabilization of EVABased Encapsulant in Field-Aged Solar Energy Modules, Polymer Degradation and Stability, 55, 347-365 (1997).

[7] A. L. Andrady, S. H. Hamid, X. Hu, A. Torikai, Effects of Increased Solar Ultraviolet Radiation on Materials, Journal of Photochemistry and Photobiology B: Biology 46, 96-103 (1998).

[8] D. E. King, F. J. Pern, J. R. Pitts, C. E. Bingham, A. W. Czanderna, "Optical Changes in Cerium-Containing Glass as a Result of Accelerated Exposure Testing" , 26th IEEE PVSC, Sept 29-Oct 3, Anaheim, California (1997)

[9] M. Ezrin, G. Lavigne, P. Klemchuk, W. Holley, S. Agro, J. Galica, L. Thomas, R. Yorgensen, Discoloration of EVA

Encapsulant in Photovoltaic Cells, ANTEC 1995.

[10] M. D. Kempe, T. Moricone, M. Kilkenny, "

Effects of Cerium Removal From Glass on Photovoltaic Module Performance and Stability ", Proc. SPIE, San Diego, CA (2009) [11] J. E. Pickett, D. A. Gibson, M. M. Gardner, Effects of Irradiation Conditions on the Weathering of Engineering Thermoplastics, Polymer Degradation and Stability, 93, 15971606 (2008)

[12] G. Jorgensen, C. Bingham, D. King, A. Lewandowski, J. Netter, K. Terwilliger, K Adamsons, Use of Uniformly Distributed Concentrated Sunlight for Highly Accelerated Testing of Coatings, ACS Conference-Service Life Prediction of Organic Coatings: Methodologies and Metrologies, (1999)

[13] J.W. Martin, J. W. Chin, T. Nguyen, Reciprocity Law Experiments in Polymeric Photodegradation: A Critical Review, Progress in Organic Coatings, 42,292-311 (2003). 


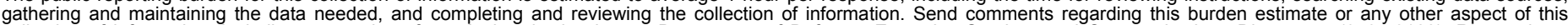

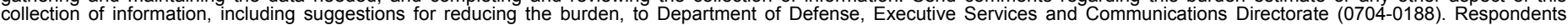

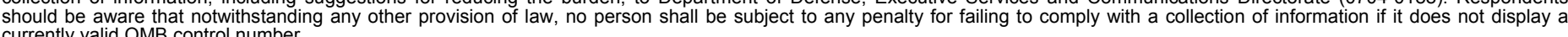

PLEASE DO NOT RETURN YOUR FORM TO THE ABOVE ORGANIZATION.

\begin{tabular}{l|l|l|}
\hline 1. REPORT DATE $(D D-M M-Y Y Y Y)$ & 2. REPORT TYPE & 3. DATES COVERED (FrOm - TO)
\end{tabular} September 2009

Technical Paper

4. TITLE AND SUBTITLE

High-Flux Stress Testing of Encapsulants for Medium-Concentration CPV Applications 5a. CONTRACT NUMBER

DE-AC36-08-GO28308

5b. GRANT NUMBER

5c. PROGRAM ELEMENT NUMBER

5d. PROJECT NUMBER

NREL/TP-520-46648

5e. TASK NUMBER

PVD91330

5f. WORK UNIT NUMBER
7. PERFORMING ORGANIZATION NAME(S) AND ADDRESS(ES)

National Renewable Energy Laboratory

1617 Cole Blvd.

Golden, CO 80401-3393
8. PERFORMING ORGANIZATION REPORT NUMBER

NREL/TP-520-46648

9. SPONSORING/MONITORING AGENCY NAME(S) AND ADDRESS(ES)

10. SPONSOR/MONITOR'S ACRONYM(S) NREL

11. SPONSORING/MONITORING AGENCY REPORT NUMBER

12. DISTRIBUTION AVAILABILITY STATEMENT

National Technical Information Service

U.S. Department of Commerce

5285 Port Royal Road

Springfield, VA 22161

13. SUPPLEMENTARY NOTES

14. ABSTRACT (Maximum 200 Words)

Concentrating photovoltaic (CPV) systems have great potential to reduce photovoltaic (PV) electricity costs because of the low cost of optical components relative to PV cells. Ultimate success of CPV will require long-term reliability, including stability of the transparent polymeric material that encapsulates the cell, and, therefore, is exposed to concentrated light. It is desireable to evaluate the UV-resistance of these materials in a reasonably short time. In this work we investigated two strategies for enhancing UV exposure, achieving a sustainable intensity of 40-45 suns UV. We applied these strategies to polydimethyl silioxane (PDMS), ethylene vinyl-acetate (EVA), ionomers, and thermoplastic polyurethanes (TPU). Superior performance was found for PDMS materials, but some of the hydrocarbon-based materials could also be suitable for CPV applications.

\section{SUBJECT TERMS}

PV; concentrating photovoltaics; high-flux stress testing; hydrocarbon-based encapsulants; ultraviolet radiation; low cost; medium concentration; quantum efficiency; solar spectrum

\begin{tabular}{l|l|l|l|l|}
\hline \multicolumn{2}{|l|}{ 16. SECURITY CLASSIFICATION OF: } & $\begin{array}{c}\text { 17. LIMITATION } \\
\text { OF ABSTRACT }\end{array}$ & $\begin{array}{c}\text { 18. NUMBER } \\
\text { OF PAGES }\end{array}$ \\
\hline $\begin{array}{l}\text { a. REPORT } \\
\text { Unclassified }\end{array}$ & $\begin{array}{c}\text { b. ABSTRACT } \\
\text { Unclassified }\end{array}$ & $\begin{array}{l}\text { c. THIS PAGE } \\
\text { Unclassified }\end{array}$ & $\begin{array}{c}\text { UL } \\
\end{array}$ &
\end{tabular}

19a. NAME OF RESPONSIBLE PERSON

19b. TELEPHONE NUMBER (Include area code) 